\title{
Matched Child Savings Accounts in Low-Resource Communities: Who Saves?
}

\author{
Leyla Karimli $^{1}$ • Fred M. Ssewamala ${ }^{2}$ - Torsten B. Neilands ${ }^{3}$. \\ Mary McKernan McKay ${ }^{4}$
}

Published online: 9 April 2015

(C) Springer International Publishing 2015

\begin{abstract}
This study examines variations in saving behavior among poor families enrolled in a Child Savings Account program for orphaned and vulnerable school-going children in Uganda. We employ multilevel analyses using longitudinal data from a cluster-randomized experimental design. Our analyses reveal the following significant results: (1) given the average number of months during which the account was open (18 months), families saved on average, USD 54.72 , which, after being matched by the program (2:1 match rate) comes to USD 164.16 - enough to cover approximately five academic terms of post-primary education; (2) children's saving behavior was not associated with quality of family relations; it was, however, significantly associated with family financial socialization; (3) family demographics were significantly associated with children's saving behavior in the matched Child Savings Account program; and (4) children enrolled in some schools saved better compared to children enrolled in other schools within the same treatment group.
\end{abstract}

Leyla Karimli

1k1706@nyu.edu

Fred M. Ssewamala

fs2114@columbia.edu

Torsten B. Neilands

torsten.neilands@ucsf.edu

Mary McKernan McKay

mary.mckay@nyu.edu

1 McSilver Institute for Poverty Policy and Research, New York University, 41 East 11th Street, 7th Floor, New York, NY 10003, USA

2 School of Social Work, Columbia University, New York, NY, USA

3 San Francisco, School of Medicine, University of California, Oakland, CA, USA

4 McSilver Institute for Poverty Policy \& Research, Silver School of Social Work, New York University, New York, NY 10003, USA
Keywords Child savings accounts · Low-resource communities $\cdot$ Children and adolescents $\cdot$ Suubi-Maka . Uganda

\section{Introduction}

Poor communities are less attractive to mainstream financial institutions due to high transaction costs of providing financial services to low-income populations. Yet, just like their nonpoor counterparts, people living in poor communities have financial emergencies and unforeseen needs that may necessitate tapping into accumulated savings. In addition, on an ongoing basis, poor people need lump sums of money to cover family-related expenses including basic needs of food, healthcare, shelter (housing), education, and any unforeseen emergencies. Savings not only help individuals and their families meet their future consumption needs, but also strengthen their ability and capacity to mitigate risks and break the cycle of intergenerational poverty. Therefore, new kinds of savings products and opportunities to access them are offered to people living in poverty.

Of recent, given the documented psychosocial and developmental impacts of saving and asset accumulation, there are several programs being implemented to connect poor people to financial institutions that can help them save and accumulate assets. Examples of these initiatives exist both in industrialized (Schreiner and Sherraden 2007) and developing countries (Ssewamala et al. 2010a; Johnson et al. 2012).

Although there are several studies that examine the impact of Child Savings Accounts in poor communities of subSaharan Africa, there are no studies (by this writing) that examine variations in saving performance in matched child savings accounts offered in sub-Saharan Africa. In other words, while faciliated with similar institutional structures, some 
participants in matched child savings accounts programs saved larger amounts and depositted more frequently than others. The question therefore is: What accounts for variations in saving behavior of children in matched child savings account programs in poor countries including those in subSaharan Africa? Can existing theories of saving behaviortested mainly in the context of western socieities - explain variations in saving behavior of children living in poor communities in sub-Saharan Africa?

Answering this question is important for several reasons. First, little is known about saving behavior in matched savings programs in sub-Saharan Africa. Significant differences in socio-economic and demographic profiles between people who live in poverty in sub-Saharan Africa and those who live in poverty in western industrialized countries warn against extrapolating western-based evidence to sub-Saharan Africa. Second, there is documented evidence of the positive psychosocial impact of participation in matched child savings accounts programs. Namely, participants in these programs reported improved mental-health functioning for both children and their caregivers (Han et al. 2013; Ssewamala et al. 2012), and for children specifically, improved educational performance (Curley et al. 2010; Ssewamala and Ismayilova 2009), and lessened intentions to engage in sexual risk-taking behavior (Ismayilova et al. 2012; Ssewamala et al. 2010b). Therefore, it is important to understand factors associated with savings performance in matched savings accounts in poor developing countries to inform policy and programming in the area of asset-accumulation for vulnerable children and their families in these (sub-Saharan African) countries. It is particularly timely as governments and organizations in sub-Saharan Africa are increasingly moving towards financial inclusion for young people - the fastest-growing population segment in the region.

\section{Factors Accounting for Saving Performance in Matched Child Savings Accounts}

We have identified three main categories of factors that can potentially account for saving performance in matched savings accounts: (1) individual characteristics (such as, age, gender, individual preferences), (2) family characteristics (such as, family demographics, family relations, family financial socialization), and (3) institutional characteristics (such as, access to financial institutions).

\section{Individual Characteristics}

Individual characteristics potentially affecting saving behavior were defined by classical and behavioral economists and psychologists, and may include an individual's age, gender, time preferences, personal motives, expectations, and future orientation.
Classical economists (Modigliani et al. 2005) argue that an individual's current consumption is a function of her lifetime resources and the rate of return on these resources, with parameters depending on age. Consequently, variation in savings among individuals is an inverted U-shaped function of age: Young and elderly individuals having fewer savings than middle-aged individuals.

Studies by behavioral economists and psychologists show that, for example, future orientation, referring to a person's outlook towards the future, may alter that person's evaluation of the economic situation and/or shape a person's time preferences, thus affecting the choice between spending and saving (Puri and Robinson 2007). Gender and age are found to be significant predictors of saving motives, and combined with attitudes and future orientation, affect saving behavior (DeVaney et al. 2007; Anong and Fisher 2013).

\section{Family Characteristics}

Family factors potentially affecting an individual's saving behavior may comprise of household characteristics (e.g., household size, number of earners in the household, presence of children), interpersonal family relations, and financial socialization within the family.

Several studies (Banerjee and Duflo 2007; Donni and Chiappori 2011) have documented that household demographics, such as age and gender of the household head, and number of children in the household, can be significant predictors of an individual's saving behavior.

The family financial socialization approach argues that children's financial behavior, including consumption patterns and expectations related to savings, are influenced by the financial behavior of their family members, particularly their parents (Gudmunson and Danes 2011; Jorgensen and Savla 2010; Kim et al. 2011). For example, a strong association was found between amounts saved by children and amounts saved by their parents, as well as between future orientation of children and that of their parents (Webley and Nyhus 2006). Family financial socialization may also alter gender roles in relation to saving, and this can account for a strong association between a child's gender and her/his saving behavior. For example, due to gender norms, female children were less involved in banking and were allowed to take part-time jobs later in age than boys (Webley and Nyhus 2013). Success of family financial socialization may be affected by interpersonal family relations, where warmth in the family relationship can contribute to children's responsiveness to the financial socialization process and thus increase the probability that children will rely on their parents' values and attitudes to learn how to attain financial responsibility (Clarke et al. 2005). 


\section{Institutional Characteristics}

In the institutional theory of saving, Sherraden and colleagues posit that an individual's ability to save and accumulate assets is altered by institutions, defined as purposefully created policies, programs, products, and services that shape opportunities, constraints, and consequences (Schreiner and Sherraden 2007; Sherraden and Assets and the poor: A new American welfare policy 1991). People save not only because of their individual choices, but also due to institutional opportunities that encourage saving behavior. Practical testing of the institutional theory of saving was done through Individual Development Accounts (IDA) - subsidized asset-building programs in the form of matched savings accounts. Participants receive matched funds (the match rate varies across programs) only for approved asset-building purposes, such as purchasing a home, investment in education, or microenterprise. Participants in IDA programs are often provided with financial education, financial counseling, and social support (e.g., counseling and encouragement to contribute to the account) (Schreiner and Sherraden 2007; Han et al. 2009; Mills et al. 2008). Child savings accounts are a form of IDA, specifically targeted to children: They are opened in a child's name with the purpose of accumulating assets to be invested in a child's future wellbeing.

\section{Methods}

\section{Data}

To address the questions of "What factors account for variations in saving behavior among children participating in matched Child Savings Account programs in sub-Saharan Africa? Can we use the existing western focused theory to explain the observable variations?"-we use data from a National Institutes of Health funded study, called Suubi-Maka (Hope for Families) implemented in southern Uganda from 2008 to 2012. Suubi-Maka is a cluster-randomized controlled trial in which ten rural public primary schools were matched on academic performance (based on the government administered primary leaving examination from the previous 3 years), were randomly assigned to a treatment group ( $n=5$ schools) and a control group ( $n=5$ schools). All children included in the study had to meet the following inclusion criteria: (1) selfidentify as an orphan - defined as a child who lost one or both parents; (2) enrolled in a public primary school located in Rakai or Masaka Districts in southern Uganda - two districts heavily affected by HIV/AIDS; (3) attending the last 2 years of primary school (an equivalent of sixth and seventh grades in the U.S. education system); (4) live within a family. For a caregiver to be included in the study, he/she had to be identified as the primary caregiver for the participating child.
Identification of the primary caregiver for a specific child was done by the child and was verified by a letter from the local council/village leaders. The study did not enroll any children living in institutions (e.g., group homes, orphanages). The Suubi-Maka study collected data from both the child and their primary caregiver ( $N=346$ dyads $)$ in three follow-up survey assessments over a period of 24 months. Baseline data were collected prior to random assignment.

Each child in the treatment group $(n=179)$ was offered a child savings account opened in his/her name. A monthly deposit of up to 20,000 Uganda shillings (an equivalent of slightly over USD 10 at the time) was matched on a monthly basis at a rate of $2: 1$. This means that if the participating child or the family members deposited the local currency equivalent of US\$10 a month, the participant would receive US\$20 in his/her savings account, totaling US\$30 in the account in 1 month. Withdrawals from the matched accounts were restricted to covering educational expenses and/or starting a family small business initiative, also referred to as a microenterprise. In addition to the matched deposit, each participant with a child savings account (CSA) could also participate in financial management workshops offered by the Suubi-Maka project. Each of the three study-partner financial institutions required a minimum deposit to open an account, which was fully covered by the Suubi-Maka project as an incentive to participants. The study intervention period ran for 20 months.

Participants in both study groups - treatment and controlreceived usual care for orphaned children in the region, which included counseling, school lunch, school uniforms, and scholastic materials.

Given the focus of this paper-which is about understanding variations in saving performance of participants in a subsidized matched savings program - we use data from the treatment group $(n=179)$. The savings data on account opening, deposits, and withdrawals come directly from the three financial institutions holding the children's savings accounts. Information was obtained in the form of quarterly bank statements received directly from the financial institutions. Data on predictor variables was collected through a 90 -minute individual instrument administered with each participating child (Child Assessment instrument) and a 60-minute individual instrument administered with each guardian (Guardian Assessment instrument).

\section{Measures}

A. Outcome variables

1. Whether a child had an active child savings account (dichotomized as Yes/No), that is, whether a family opened an account and deposited an amount greater than zero, at least once.

2. Frequency of depositing, a continuous variable calculated as a ratio of times of making deposits to the total number 
of months the account was opened. We use ratio, because the total number of months during which the CSA was opened differs across study participants. For example, if the CSA had been open for 10 months, and the frequency of depositing in this CSA equaled 0.30 - it would mean that deposits were made during three out of ten total months following the opening of the CSA.

3. Average monthly savings per participant, a continuous variable obtained by subtracting total unmatched withdrawals from total deposits, and dividing this amount by the number of months in which the participant made deposits.

B. Predictor variables

Individual characteristics include the participating child's age, gender, and orphanhood status ("double orphan", "single maternal orphan", "single paternal orphan"), and the child's future orientation. To measure future orientation, we used the Beck Hopelessness Scale, the child's educational plans after completing primary school (dichotomized as $0=$ "Not planning to start secondary school", and 1="Planning to start secondary school"), and the child's educational aspirations.

The Beck Hopelessness Scale measures a respondent's pessimistic outlook and negative expectations about events in her/his future. It is a 20-item self-report inventory, where each item is a binary variable with two response categories (True/False). The score ranges from 0 (no hopelessness) to 20 (absence of all hope). The measure has high internal consistency (Cronbach's alpha $=0.68$ at baseline; and Cronbach's alpha $=0.7$ at both 12- and 24-month follow-up assessments).

Child educational aspirations is an ordinal variable corresponding to the question from the Child Assessment instrument that asks, "Thinking back on the questions you have answered so far, how far do you really believe you will go in school?". The measure has five response categories: $1=$ "Drop at any stage before completing secondary school", $2=$ "Complete secondary school and stop", $3=$ "Go on to technical college", $4=$ "Go on to the university to get a degree", 5="Finish university and go on to graduate school to get a second degree".

Family characteristics include family relations, family financial socialization, and household demographics. To measure family relations, two scales are used: family cohesion reported by the child and family cohesion reported by the guardian. Both scales are an average score for an index of 26 items; the higher the score, the higher the level of family cohesion. The measure has high internal consistency for both children (Cronbach's alpha is 0.79 at baseline, 0.78 at 12month follow-up, and 0.79 at 24-month follow-up) and guardians (Cronbach's alpha is 0.73 at baseline, 0.77 at 12-month follow-up, and 0.79 at 24-month follow-up).

Family financial socialization is measured by the following indicators: (1) Child's knowledge of the guardian saving for her/him $(1=$ "Child does not know whether parent/guardian saves for her/him", $2=$ "Child knows that parent/guardian does not save for her/him", and 3="Child knows that parent/guardian saves for her/him"); (2) Guardian's reported willingness to build assets (a continuous variable: The higher the score, the higher the guardian's willingness to build assets); and (3) Guardian's self-reported saving (dichotomized as $1=$ "Currently have money saved somewhere" and $0=$ " Currently do not have any money saved anywhere").

Household demographics are measured by the number of earners in the household (dichotomized as "single-earner family"/“double-earner family"), number of children in the household, guardian's age and gender, and type of guardian ("parents", "grandparents", and "other relatives").

Institutional characteristics are measured by constructing a measure "Financial institution where CSA was opened" with three response categories representing the three financial institutions holding the CSAs in the study: (1) Kakuuto Microfinance; (2) Centenary Rural Development Bank and; (3) DFCU Bank. The financial institutions where the CSAs were opened did not change over the course of study. Once the account was opened and activated, it could not be transferred from one institution to another.

\section{Analyses}

This paper examines variations in saving behavior of children enrolled in a matched child savings account program. For that reason, we focus exclusively on participants in the treatment group of the Suubi-Maka study ( $n=5$ schools; 179 participants) for whom administrative data on savings were availed by the financial institutions where the CSAs were held. Survey data on children and their guardians (179 dyads) was collected in three waves: at baseline, and at 12- and 24month follow-up assessments.

\section{Clustered nature of data}

Based on the study design, observations were nested within schools with significant intraclass correlations among schools. Statistical models described below and data analyses (performed in Stata 12) account for the correlation due to school-clustered repeated-measures nature of the data. Univariate analyses describing the sample as well as bivariate analyses were conducted using the Stata survey command suite (-svy-) to account for cluster randomization at the school level. We report adjusted F-statistics to examine individuallevel variations at baseline while accounting for potential correlation between same-school observations.

2. Selecting predictors to be included in final multiple regression models 
After the initial selection of potential predictors (based on the earlier review of factors accounting for saving performance in matched child savings accounts), we conducted bivariate analyses (using -svy regress- for continuous outcome measures and -svy logit- for binary outcome measures) to test the relationship of each predictor variable with each of the outcome measures (results of bivariate analyses are presented in Appendix 1). Predictors that had significant bivariate association with outcome measures were further included in multiple regression models. The multiple regression models including only predictors that had significant bivariate associations with outcome measures at $p<0.05$ are hereafter referred to as "reduced models".

We also conducted analyses to identify potential suppressor variables. Suppressor variables are predictors that (1) are not correlated with the outcome measure; (2) are correlated with other predictors, thus accounting for some outcome-irrelevant variation in those predictors; (3) do not pose the threat of multicollinearity; and (4) improve the overall predicting power of the model. Including suppressor variables in final multiple regression models minimizes risk of false indication of no relationship that is the risk of rejecting an actually significant relationship (Friedman and Wall 2005; Rubin and Babbie 2008).

To identify potential suppressor variables, we first examined bivariate relationships between pairs of all predictor variables. Predictors that had no statistically significant relationships with any other predictors were excluded from further analyses. All the predictors that had statistically significant relationships between each other were tested for multicollinearity using the tolerance value and variance inflation factor (VIF). A rule of thumb is that a tolerance value less than 0.1 and a VIF value greater than 10 may indicate the presence of multicollinearity (Lin 2008; Curto and Pinto 2011). The tolerance value for each of the bivariate relationships among our predictors was above 0.7 , and none of the VIF values was higher than 1.4. Given the rule of thumb mentioned earlier, these values suggest there is no risk of multicollinearity between predictor variables. Then, each of the predictors not excluded at the previous step were added separately into reduced regression models in order to test if adding a particular predictor improves the model fit (results are presented in Appendix 2). Models were compared using the modified Akaike Information Criterion quasi-likelihood under independence model criterion called (QIC). A model with the smallest QIC value had the best subset of covariates and, therefore, was the best-fitting model (Cui 2007).

The final multiple regression models - hereafter referred to as "full models" - included predictors that hadstatistically significant bivariate relationships with outcome measures (i.e., reduced model) plus predictors that —although not having significant bivariate association with outcome measures - had statistically significant bivariate relationships with other predictors, and their inclusion in the model improved the model fit (asmeasured by QIC).

\section{The multiple regression analyses}

The multiple regression analyses were run using generalized estimating equation (GEE) models with robust standard errors clustering on individual observations (xtgee command in Stata 12). GEE estimate population-averaged treatment effects (instead of subject-specific treatment effect) and account for within-subject correlations among responses over time and allow for time-varying covariates. In accordance with the 30/30 rule of thumb for handling multilevel data (Hox 2010), the number of schools in our study was too small $(n=5)$ to treat schools as a level. Therefore, schools were treated as nested fixed effects.

There are two groups of participants in the study. Those who had active accounts - defined as those who had opened a CSA and made at least one deposit into their CSA and those who did not have active accounts - defined as those who either did not open a CSA or opened a CSA but did not make any deposits. Furthermore, information on the average monthly amount saved in the CSA and the frequency of depositing in the CSA was applicable only to the participants who had active CSAs. Against this backdrop, in order to improve the accuracy of our inferences (accounting for both groups), we employ Heckman's selection model and use of the inverse Mills ratio to account for the presence of limited dependent variables (Heckman 2013). First, we calculate the probability for a treatment group participant to have an active CSA. This probability was estimated using Stata's command xtgee with a logit link that was run on the outcome measure having an active CSA. Second, using the obtained probability, we calculate the inverse Mills ratio, lamb$\mathrm{da}$, to account for the fact that only part of the treatment group sample had values for the average monthly amount saved in the CSA and frequency of depositing in the CSA. The inverse Mills ratio is a ratio between the standard normal probability density function and standard normal cumulative distribution function. Finally, we included lambda as an additional predictor into xtgee regressions run on average monthly amount saved in the CSA and frequency of depositing in the CSA. A statistically significant coefficient on lambda would signify a selection bias. We correct for this bias by including the inverse Mills ratio into the regression model as a covariate.

\section{Results}

\section{Description of Measures}

As shown in Table 1, at study initiation/baseline, participantswith a mean age of 13 years for children and 44 years for guardians-lived in households with an average of three children. Girls represented $65 \%$ of the sample. The majority ( $58 \%$ ) of 
Table 1 Description of the sample

$\begin{array}{ll}\text { Baseline }(n=179) \quad \begin{array}{l}\text { 12-month follow-up } \\ (n=171)\end{array} & \begin{array}{l}\text { 24-month follow-up } \\ (n=166)\end{array} \\ \text { Percent or mean [95\% confidence interval }] & \end{array}$

\begin{tabular}{|c|c|c|c|}
\hline \multicolumn{4}{|l|}{ Individual characteristics } \\
\hline Child's age (mean; range, 10-17) & $13[13 ; 14]$ & $14[14 ; 15]$ & $15[15 ; 16]$ \\
\hline Female child (\%) & $65.4[49.1 ; 78.7]$ & $65.5[48.7 ; 79.2]$ & $63.9[46.6 ; 78.2]$ \\
\hline \multicolumn{4}{|l|}{ Orphanhood status $(\%)$} \\
\hline Double orphan & $23[17.6 ; 29.5]$ & $24.3[18.5 ; 31.2]$ & $21.5[14.1 ; 31.3]$ \\
\hline Single paternal orphan & $57.9[48.7 ; 66.5]$ & $57.4[50 ; 64.5]$ & $58.9[48.2 ; 68.8]$ \\
\hline Single maternal orphan & $19.1[13.1 ; 27]$ & $18.3[13.4 ; 24.7]$ & $19.6[16.4 ; 23.3]$ \\
\hline Beck Hopelessness Scale (mean; range, 0-20) & $6[5 ; 6]$ & $3[3 ; 4]$ & $3[2 ; 3]$ \\
\hline \multicolumn{4}{|l|}{ Children's educational aspirations (\%) } \\
\hline Drop before completing secondary school & $11.7[5.5 ; 23.4]$ & $6.7[2.4 ; 17.9]$ & $5.3[1.6 ; 15.6]$ \\
\hline Complete secondary school and stop & $12.9[7.5 ; 21.2]$ & $3.7[1.1 ; 11.6]$ & $3.9[0.8 ; 18.01]$ \\
\hline Go on to technical college & $8.4[1.5 ; 35.9]$ & $4.9[1.6 ; 13.8]$ & $9.9[4.7 ; 19.4]$ \\
\hline Go on to the university & $25.1[18.3 ; 33.5]$ & $41.1[23.2 ; 61.7]$ & $59.2[48.5 ; 69.2]$ \\
\hline Finish university and go on to graduate school & $41.9[30.5 ; 54.3]$ & $43.6[30.9 ; 57.2]$ & $21.7[14.2 ; 31.7]$ \\
\hline \multicolumn{4}{|l|}{ Children’s educational plans (\%) } \\
\hline Not planning to start secondary school & $8.4[5 ; 13.7]$ & $4.9[1.5 ; 15.1]$ & $2.6[0.6 ; 10.1]$ \\
\hline Planning to start secondary school & $91.6[86.3 ; 95.01]$ & $95.1[84.9 ; 98.5]$ & $97.4[89.9 ; 99.4]$ \\
\hline \multicolumn{4}{|l|}{ Family characteristics } \\
\hline Family cohesion reported by child (mean; range, $1-5$ ) & $3.8[3.7 ; 3.9]$ & $3.9[3.8 ; 3.9]$ & $3.9[3.8 ; 4]$ \\
\hline Family cohesion reported by guardian (mean; range, $1-5$ ) & $3.8[3.8 ; 3.9]$ & $3.8[3.8 ; 3.9]$ & $3.9[3.8 ; 3.9]$ \\
\hline \multicolumn{4}{|l|}{ Child's knowledge about guardian saving for her/him (\%) } \\
\hline Child doesn't know & $16.8[8.4 ; 30.7]$ & $15.8[5.2 ; 39.1]$ & $14.5[11 ; 19]$ \\
\hline Child knows that guardian does not save & $62[50 ; 73]$ & $24[12.5 ; 41.1]$ & $38.2[20.5 ; 60]$ \\
\hline Child knows that guardian saves & $23.2[17.1 ; 26]$ & $60.2[31.9 ; 83.1]$ & $47.3[27.3 ; 68.2]$ \\
\hline \multicolumn{4}{|l|}{ Guardian's reported willingness to build assets (\%) } \\
\hline Spend all of it & $9[5.2 ; 15.1]$ & $14.9[3.7 ; 44.3]$ & $8[4 ; 15.7]$ \\
\hline Spend most of it & $5[1.3 ; 17.8]$ & $6.9[2.9 ; 15.3]$ & $11.5[7.1 ; 18.1]$ \\
\hline Spend half, save half & $29.6[23.4 ; 36.7]$ & $40.8[21.2 ; 63.8]$ & $36.2[25.5 ; 48.5]$ \\
\hline Save most of it & $5.6[2.1 ; 13.85]$ & $5.2[1.9 ; 13]$ & $5.2[1.2 ; 19.9]$ \\
\hline Save all of it & $6.7[4.9 ; 9.1]$ & $2.3[0.6 ; 8.1]$ & $1.7[0.2 ; 11.2]$ \\
\hline Buy a cow, goat, or other animal that would eventually bring money & $44.1[36.7 ; 51.8]$ & $29.9[14.7 ; 51.3]$ & $37.4[26.65 ; 49.5]$ \\
\hline Guardian saves $(\%)$ & $39.66[19.76 ; 63.71]$ & $55.75[44.56 ; 66.38]$ & $64.94[50.66 ; 76.97]$ \\
\hline Single-earner family (\%) & $64.25[56.7 ; 71.1]$ & $61.3[47.6 ; 73.4]$ & $63.7[50.7 ; 75]$ \\
\hline Number of children in the household (mean; range, $0-9$ ) & $3[3 ; 4]$ & $3[3 ; 4]$ & $3[3 ; 4]$ \\
\hline Guardian's age (mean; range, 18-87) & $44[37 ; 51]$ & $45[38 ; 52]$ & $46[38 ; 53]$ \\
\hline Female guardian $(\%)$ & $77.6[60 ; 89]$ & $77.6[62.4 ; 87.8]$ & $77.6[63.5 ; 87.3]$ \\
\hline \multicolumn{4}{|l|}{ Type of guardian (\%) } \\
\hline Parents & $40.2[28 ; 53.8]$ & $40.2[30 ; 51.8]$ & $43.1[32.6 ; 54.3]$ \\
\hline Grandparent & $21.2[9.6 ; 40.6]$ & $21.8[10.45 ; 40.1]$ & $20.7[9.7 ; 38.7]$ \\
\hline Other relatives & $38.6[28.9 ; 49.2]$ & $37.9[30.7 ; 45.8]$ & $36.2[28.5 ; 44.7]$ \\
\hline
\end{tabular}

children in the sample were single paternal orphans (father died); $19 \%$ of children were single maternal orphans (mother died), and $23 \%$ were double orphans (both parents died).

Table 2 presents saving performance in child savings accounts in the Suubi-Maka study. Out of 179 families enrolled in the treatment group, $66 \%(n=118)$ opened child savings accounts and deposited money as a result of participation in the study. In other cases, accounts were opened but never activated $(7.8 \%)$, or accounts were opened but no deposits were made during the study 
Table 2 Saving performance in child savings accounts $(N=179)$

\begin{tabular}{|c|c|c|c|c|}
\hline \multirow[t]{2}{*}{ Variable } & \multicolumn{2}{|c|}{ 12-month follow-up } & \multicolumn{2}{|c|}{ 24-month follow-up } \\
\hline & $\mathrm{N}$ & $\begin{array}{l}\text { Percent or mean } \\
{[95 \% \text { confidence }} \\
\text { interval] }\end{array}$ & $\mathrm{N}$ & $\begin{array}{l}\text { Percent or mean } \\
{[95 \% \text { confidence }} \\
\text { interval] }\end{array}$ \\
\hline \multicolumn{5}{|l|}{ Opening child savings accounts (\%) } \\
\hline Opened, activated, and deposited & 112 & $62.6[38.7 ; 81.6]$ & 118 & $66[41.5 ; 84.1]$ \\
\hline $\begin{array}{l}\text { Opened, activated, but never } \\
\text { deposited }\end{array}$ & 14 & $7.8[4.8 ; 12.6]$ & 14 & $7.8[5.1 ; 11.9]$ \\
\hline Opened, but never activated & 11 & $6.1[0.6 ; 40.8]$ & 14 & $7.8[1 ; 43.6]$ \\
\hline Did not open & 42 & $23.5[8.7 ; 49.6]$ & 33 & $18.4[5.6 ; 46.1]$ \\
\hline $\begin{array}{l}\text { Average number of month account } \\
\text { was open (mean) }\end{array}$ & 137 & $7.4[5.9 ; 8.8]$ & 146 & $17.8[16.1 ; 19.6]$ \\
\hline $\begin{array}{l}\text { Frequency of depositing ( } \% \text { of } \\
\text { months account was open) }\end{array}$ & 112 & $47[36 ; 59]$ & 118 & $29[18 ; 40]$ \\
\hline Average amount saved (mean) & 112 & $9,203[6,410 ; 11,996]$ & 118 & $5,477[2,437 ; 8,516]$ \\
\hline Lower quartile ( $25 \%$ percentile) & & $3,333[2,500 ; 4,485]$ & & $1,053[883 ; 1,655]$ \\
\hline Upper quartile (75 \% percentile) & & $15,000[10,000 ; 16,667]$ & & $7,383[5,263 ; 11,510]$ \\
\hline $\begin{array}{l}\text { Financial institution where CSA } \\
\text { was opened }(\%)\end{array}$ & 137 & & 146 & \\
\hline Kakuuto Microfinance & 12 & $8.8[0.3 ; 73]$ & 12 & $8.2[0.3 ; 72]$ \\
\hline Centenary Bank & 42 & $30.7[2.6 ; 88]$ & 51 & $35[4.2 ; 87]$ \\
\hline DFCU & 83 & $60.6[8 ; 96.5]$ & 83 & $57[8.8 ; 95]$ \\
\hline
\end{tabular}

intervention period $^{1}(7.8 \%)$. In $18.4 \%$ of cases $(n=33)$, accounts were never opened. Most of the accounts were opened by the 12-month follow-up assessment period.

Out of the 146 accounts opened, $8.2 \%(95 \% \mathrm{CI}=0.3,72)$ were opened in Kakuuto Microfinance Institution; $35 \%$ (95 \% $\mathrm{CI}=4.2,87)$ were opened in Centenary Bank, and $57 \%(95 \%$ $\mathrm{CI}=8.8,95)$ were opened in DFCU Bank. Financial institutions were unevenly distributed across the schools, which may explain significant variation in $95 \%$ confidence interval estimates. As explained earlier, the child and her/his family could choose in which financial institution to open the CSA among the three institutions that partnered with the study. There was no assignment of any particular financial institution to any particular school.

By the end of the intervention, the average savings per participant was Uganda Shillings (UGX) 5,477 per month (an equivalent of USD 3.04 with an average exchange rate of USD $1=$ UGX 1,800 - at the time of the study). In the lower quartile, participants saved an average of UGX 1,053. In the upper quartile, the average amount saved was UGX 7,383. Average monthly savings were higher at 12-month follow-up. More specifically, by wave 2, participants saved an average of UGX 9,203 per month, with UGX 3,333 saved in the lower quartile, and UGX 15,000 saved in the upper quartile.

By the end of the intervention, the average frequency of depositing equaled to 0.29 , that is, participants deposited $29 \%$

\footnotetext{
${ }^{1}$ No deposits were made on these accounts beyond the opening amount provided by the project.
}

of the months following the activation of the account. Similar to average monthly savings, the frequency of depositing funds in the CSAs was higher at 12-month follow-up. By wave 2, participants deposited, on average, $47 \%$ of the months following the activation of the account.

\section{Regression Analyses}

In Table 3, we present the results of full GEE regression models fit for each of the three outcome measures.

Results show that older children in the treatment group were more likely to have an active CSA (odds ratio $=2.55$, $95 \% \mathrm{CI}=2.01,3.24)$ and saved a larger monthly amount in their CSA $(B=0.67,95 \% \mathrm{CI}=0.34,0.99)$ than younger children in the treatment group. Furthermore, compared with children who had lower scores on the Beck Hopelessness Scale, children with higher scores on the Beck Hopelessness Scale were less likely to have an active CSA (odds ratio $=0.85,95 \%$ $\mathrm{CI}=0.77,0.94)$, and deposited less frequently $(\mathrm{B}=-0.04$, $95 \% \mathrm{CI}=-0.06,-0.01)$. Children who planned to start secondary school after completing primary school deposited more frequently $(\mathrm{B}=0.13,95 \% \mathrm{CI}=0.04,0.23)$ than children who did not plan on starting secondary school.

Furthermore, compared with children who did not know if their guardians saved for them, children who knew their guardians saved for them were more likely to have active CSAs (odds ratio $=6.1,95 \% \mathrm{CI}=3.08,12.1$ ), save a larger monthly amount in their $\mathrm{CSA}(\mathrm{B}=1.51,95 \% \mathrm{CI}=0.53,2.5)$, and deposit more frequently $(\mathrm{B}=0.35,95 \% \mathrm{CI}=0.21,0.49)$. 
Table 3 Full regression models

\begin{tabular}{|c|c|c|c|c|c|c|}
\hline \multirow[t]{2}{*}{ Variables } & \multicolumn{2}{|c|}{ Have active CSA (yes/no) } & \multicolumn{2}{|c|}{$\begin{array}{l}\text { Average monthly amount } \\
\text { saved in CSA (log) }\end{array}$} & \multicolumn{2}{|c|}{$\begin{array}{l}\text { Frequency of depositing } \\
\text { in CSA }\end{array}$} \\
\hline & Odds ratio & $95 \% \mathrm{CI}$ & B coef & $95 \% \mathrm{CI}$ & $B$ coef & $95 \% \mathrm{CI}$ \\
\hline \multicolumn{7}{|l|}{ Individual characteristics } \\
\hline Child's age & $2.55 * * *$ & {$[2.01 ; 3.24]$} & $0.67 * * *$ & {$[0.34 ; 0.99]$} & & \\
\hline Beck Hopelessness Scale & $0.85 * *$ & {$[0.77 ; 0.94]$} & -0.14 & {$[-0.29 ; 0.00]$} & $-0.04 * *$ & {$[-0.06 ;-0.01]$} \\
\hline $\begin{array}{l}\text { Educational plans: planning to start secondary } \\
\text { school }\end{array}$ & & & & & $0.13 * *$ & {$[0.04 ; 0.23]$} \\
\hline \multicolumn{7}{|l|}{ Family characteristics } \\
\hline Family cohesion reported by child & & & & & 0.04 & {$[-0.01 ; 0.09]$} \\
\hline $\begin{array}{l}\text { Child knows that guardian does not save for her/ } \\
\text { him }\end{array}$ & 0.63 & {$[0.34 ; 1.19]$} & -0.61 & {$[-1.61 ; 0.39]$} & $-0.08 *$ & {$[-0.15 ;-0.01]$} \\
\hline Child knows that guardian saves for her/him & $6.1 * * *$ & {$[3.08 ; 12.1]$} & $1.51 * *$ & {$[0.53 ; 2.5]$} & $0.35 * * *$ & {$[0.21 ; 0.49]$} \\
\hline Guardian's reported willingness to build assets & & & $-0.23 * *$ & {$[-0.39 ;-0.07]$} & & \\
\hline Guardian reports saving & $3.83 * * *$ & {$[2.27 ; 6.49]$} & 0.55 & {$[-0.20 ; 1.30]$} & $0.27 * * *$ & {$[0.15 ; 0.4]$} \\
\hline Number of earners: single-earner & & & -0.27 & {$[-0.88 ; 0.34]$} & -0.04 & {$[-0.10 ; 0.02]$} \\
\hline Guardian gender: female guardian & & & & & $0.1 * * *$ & {$[0.05 ; 0.16]$} \\
\hline Guardian's age & $1.04 *$ & {$[1.01 ; 1.07]$} & & & & \\
\hline Type of guardian: grandparent & 0.45 & {$[0.14 ; 1.45]$} & & & & \\
\hline Type of guardian: other relatives & $0.45 *$ & {$[0.24 ; 0.85]$} & & & & \\
\hline \multicolumn{7}{|l|}{ School fixed effects ${ }^{\mathrm{a}}$} \\
\hline School 2 (Kyotera, Rakai district) & 0.50 & {$[0.15 ; 1.58]$} & -0.41 & {$[-1.42 ; 0.60]$} & -0.07 & {$[-0.19 ; 0.05]$} \\
\hline School 3 (Kimaanya, Masaka district) & 0.79 & {$[0.25 ; 2.45]$} & -0.78 & {$[-1.81 ; 0.24]$} & -0.04 & {$[-0.14 ; 0.05]$} \\
\hline School 4 (Mayanja, Rakai district) & 0.35 & {$[0.08 ; 1.43]$} & $-1.35^{*}$ & {$[-2.57 ;-0.14]$} & -0.02 & {$[-0.12 ; 0.08]$} \\
\hline School 5 (Ndegeya, Masaka district) & $0.2 *$ & {$[0.05 ; 0.7]$} & -1.00 & {$[-2.22 ; 0.22]$} & $-0.17 * * *$ & {$[-0.26 ;-0.07]$} \\
\hline Constant & $3.08 \mathrm{e}-07 * * *$ & {$[6.56 \mathrm{e}-09-.00001]$} & -1.74 & {$[-7.06 ; 3.57]$} & $-0.46^{* *}$ & {$[-0.78 ;-0.13]$} \\
\hline Observations & 505 & & 361 & & 405 & \\
\hline Number of child ID & 179 & & 146 & & 146 & \\
\hline Mill's lambda & & & $-0.87 * *$ & {$[-1.41 ;-0.34]$} & $0.2 * *$ & {$[0.06 ; 0.34]$} \\
\hline
\end{tabular}

Boldface type indicates statistically significant results

${ }^{a}$ Reference category is School 1-Kabuwoko, Rakai district. By the study design, schools were randomly assigned to the control and treatment group. All schools are comparable, and no inherent characteristics guided the selection of schools. Therefore, the reference category was chosen arbitrarily

$* * * p<0.001, * * p<0.01,{ }^{*} p<0.05$

Moreover, compared to children who did not know if their guardians saved for them, children who knew their guardians did not save for them deposited less frequently $(\mathrm{B}=-0.08$, $95 \% \mathrm{CI}=-0.15,-0.01)$.

The proportion of children who had active CSAs was greater among children whose guardians reported having saved money (odds ratio $=3.83,95 \% \mathrm{CI}=2.27,6.49$ ), compared to children whose guardians reported not having saved money. Similarly, children whose guardians reported having saved money deposited more frequently in the CSA $(B=0.27$, $95 \% \mathrm{CI}=0.15,0.4)$ than children whose guardians reported not having saved money.

Children whose guardian reported a greater willingness to build assets saved smaller average monthly amounts $(\mathrm{B}=$ $-0.23,95 \% \mathrm{CI}=-0.39,-0.07)$, compared to children whose guardians reported a lower willingness to build assets. The highest score on a guardian's willingness to build assets corresponds to a guardian's reported disposition to invest money into non-monetary assets, such as "cow, goat, pig or other animal that would eventually bring money". It is therefore possible that a greater willingness to build assets is associated with lower monetary savings in the CSA.

Children cared for by female guardians deposited more frequently $(\mathrm{B}=0.1,95 \% \mathrm{CI}=0.05,0.16)$ than children cared for by male guardians. Furthermore, children who were cared for by other relatives were less likely to have active CSAs (odds ratio $=0.45,95 \% \mathrm{CI}=0.24,0.85$ ) than children who were cared for by a living parent. Similarly, children who were cared for by older guardians were more likely to have active CSAs (odds ratio $=1.04,95 \%$ $\mathrm{CI}=1.01,1.07)$ than children who were cared for by younger guardians. 
We find significant school effects on children's saving performance in the CSAs. More specifically, compared with children enrolled in School 1 (Kabuwoko), children enrolled in School 5 (Ndegeya) were less likely to have active CSAs (odds ratio $=0.2,95 \% \mathrm{CI}=0.05,0.7$ ) and deposited less frequently $(\mathrm{B}=-0.17,95 \% \mathrm{CI}=-0.26,-0.07)$. Also, compared to children enrolled in School 1, children enrolled in School 4 (Mayanja) saved smaller average monthly amounts in their CSAs $(\mathrm{B}=-1.35,95 \% \mathrm{CI}=-2.57,-0.14)$. We are not sure what accounts for these school differences in savings.

As indicated earlier, we used Heckman's selection model to account for a potential selection bias that could occur because the average monthly amount saved in the CSA, and the frequency of depositing in the CSA was observed only for a part of the treatment sample-i.e., for participants who had an active CSA. As shown in Table 3, the coefficient for Mills lambda was statistically significant for both the average monthly amount saved in the CSA ( $\mathrm{B}=-0.87,95 \% \mathrm{CI}=$ $-1.41,-0.34)$ and the frequency of depositing in the CSA $(B=0.2,95 \% C I=0.06,0.34)$. These results suggest that the selection bias did indeed occur and was corrected for by incorporating the inverse Mills ratio into the regression models.

\section{Discussion}

The results point to several findings: First, children in SuubiMaka saved on average USD 3.04 per month. Given the average number of months when the account was open (18 months), children saved on average USD 54.72, which, after being matched by the program (with a 2:1 match rate), comes to USD 164.16. These savings, although modest, can cover the costs of a child's post-primary education, thus constituting an important investment into a child's wellbeing. Given the average cost of approximately Uganda Shillings 65,000 per academic term in a typical public secondary school in the study area (rural Rakai District) the saved amount is enough to cover approximately five academic terms.

Second, children's saving behavior in a child savings account was not associated with quality of family relations (measured through family cohesion reported by children, and family cohesion reported by guardians); it was, however, significantly associated with family financial socialization. More specifically, children's knowledge that their guardian was saving for them was positively associated with the likelihood of having an active CSA, average monthly amount saved, and frequency of depositing funds in the CSA. Similarly, the guardian's self-reported saving was positively associated with the likelihood that the child had an active account as well as the frequency of depositing in the CSA. This finding, further elaborated and examined, can potentially contribute to the body of literature on the relationship between a caregiver's financial behavior and a child's financial behavior (in this case, orphaned and vulnerable children in sub-Saharan Africa). To further expand our understanding, it would be important to examine who, within the family, made decisions on savings and how these decisions were communicated among the family members. Also, a more robust study design could help to tease-out the possible reverse causation likely to occur between family financial socialization and a child's saving behavior. It is possible that a child's knowledge of his/her guardian's behavior and the guardian's self-reported saving are an outcome of the guardian's saving behavior, rather than predictors of a child's saving behavior.

Third, findings support the hypotheses that specific family demographics are significantly associated with children's saving behavior in matched child savings account programs. More specifically, results suggest that children cared for by older guardians were more likely to have active CSAs than children cared for by younger guardians. Also, children cared for by other relatives were less likely to have active CSAs than children cared for by a living parent. Significant association between specific caregiver characteristics (i.e., age and type of caregiver) and the likelihood of having an active CSA can potentially serve as a starting point for further research on family-level decision-making with regard to saving for orphaned and vulnerable children. Additionally, results suggest that children cared for by female guardians deposited more frequently than children cared for by male guardians. This finding adds to earlier studies stressing the importance of matrilineal support (Karimli et al. 2012; Oleke et al. 2005) in the care and support of orphaned and vulnerable children.

Finally, we found that school is a factor. Children enrolled in some schools saved better compared with children enrolled in other schools within the treatment group. One explanation for this finding could be because of the physical proximity of some schools to financial institutions. Indeed, one would be justified to assume that, when children attend schools closer to the bank, they are more likely to deposit money into their accounts - since they would not incur transport expenses for depositing money into their savings accounts. However, in our study, children in the schools that were in closer proximity to the financial institutions (for example, School 4: Mayanja and School 5: Ndegeya) did not necessarily save better, compared with children in the schools that were more distant from financial institutions (for example, School 1: Kabuwoko). Therefore, alternative explanations are needed to explain the variation in saving performance across schools. It is possible that our findings are capturing specific unobservable school characteristics (e.g., quality of teacher-child interactions - which could not be controlled for at baseline). Further research is needed to advance our understanding of what exactly accounts for variation in saving performance across different schools.

To conclude, financial asset accumulation in the form of saving money may be essential for low-income individuals in countries with no public welfare system — where having some money 
saved (however modest the savings) may make the difference between starvation and being able to feed one's family. Findings of our study contribute to an understanding of factors that account for saving behavior in matched child savings account programs in Uganda. However, further research is needed to understand who, within the family, decides to save in child savings account and how this decision is implemented (in other words, where the savings come from). It is also important to know whether the decision to save in child savings account varies by child's status (orphan vs. biological child) or health condition (HIV-positive child vs. HIV-negative child). Addressing these questions would be an important contribution to the knowledgebase on the feasibility of social welfare policies focused on assetbuilding (in this case, savings) for people who live in poverty.
Acknowledgments Financial support for Suubi-Maka: A FamilyBased Economic Empowerment Model for Orphaned Children in Uganda was provided by the National Institute of Mental Health (R34 MH081763; Principal Investigator: Fred M. Ssewamala). The content is solely the responsibility of the authors and does not necessarily represent the official views of the National Institute of Mental Health or the National Institutes of Health.

We are grateful to Mary McKay, Jane Waldfogel, Proscovia Nabunya, Jennifer Nattabi, Vilma Ilic, and the Suubi Research Team in Uganda. We are also thankful to all the children and their caregivers who agreed to participate in the Suubi-Maka study.

Human Participant Protection The study was approved by Columbia University Institutional Review Board (IRB \#AAAD2525), and the Uganda National Council for Science and Technology (ref SS 1540). The study protocol is registered in the ClinicalTrials. Gov database (ID\# NCT01180114).

\section{Appendix}

Table 4 Bivariate relationship between predictors and outcome measures

\begin{tabular}{|c|c|c|c|}
\hline & $\begin{array}{l}\text { Having active } \\
\text { CSA }\end{array}$ & $\begin{array}{l}\text { Average monthly } \\
\text { amount saved }\end{array}$ & $\begin{array}{l}\text { Frequency of } \\
\text { depositing }\end{array}$ \\
\hline \multicolumn{4}{|l|}{ Individual characteristics } \\
\hline Child's age & $130.68 * * *$ & $108.58 * * *$ & 3.06 \\
\hline Child's gender & 0.52 & 0.12 & 0.08 \\
\hline Child's orphanhood status & 1.39 & 0.22 & 0.48 \\
\hline Beck Hopelessness Scale & $20.13 * *$ & $98.18 * * *$ & $31.15 * *$ \\
\hline Child's educational aspirations & 0.47 & 0.86 & 2.77 \\
\hline Child's educational plans & 4.99 & 6.2 & $75.43 * * *$ \\
\hline \multicolumn{4}{|l|}{ Family characteristics } \\
\hline Family cohesion reported by child & 0.77 & 2.88 & $23.38 * *$ \\
\hline Family cohesion reported by guardian & 0.01 & 1.41 & 0.38 \\
\hline Child's knowledge about guardian saving for her/him & $40.61 * *$ & $44.30 * *$ & $50.56 * *$ \\
\hline Guardian's reported willingness to build assets & 3.57 & $21.66 * *$ & 7.33 \\
\hline Guardian's self-reported saving & $58.39 * *$ & $15.92 *$ & $24.33 * *$ \\
\hline Number of earners in the family & 4.12 & $12.09 *$ & $8.31 *$ \\
\hline Number of children in the household & 0.35 & 0.11 & 0.14 \\
\hline Guardian's age & 0.68 & 1.2 & 0.03 \\
\hline Guardian's gender & 0.03 & 1.5 & $13.07 *$ \\
\hline Type of guardian & 0.76 & 2.1 & 0.93 \\
\hline \multicolumn{4}{|l|}{ Institutional characteristics } \\
\hline Financial institution where CSA was opened & 0.09 & 0.0001 & 0.77 \\
\hline
\end{tabular}

Boldface type indicates statistically significant results. Design-based F (1, 4)-statistics are reported, which accounts for potential correlation between same-school observations

$* * * p<0.001, * * p<0.01, * p<0.05$ 
Table 5 Separate analyses for individual predictors

\begin{tabular}{|c|c|c|c|c|c|c|}
\hline \multirow[t]{2}{*}{ Variables } & \multicolumn{2}{|c|}{ Have active CSA (yes/no) ${ }^{a}$} & \multicolumn{2}{|c|}{$\begin{array}{l}\text { Average monthly amount } \\
\text { saved in } \mathrm{CSA}^{\mathrm{b}}\end{array}$} & \multicolumn{2}{|c|}{$\begin{array}{l}\text { Frequency of depositing } \\
\text { in } \text { CSA }^{c}\end{array}$} \\
\hline & Odds ratio & $95 \% \mathrm{CI}$ & $B$ coef & $95 \% \mathrm{CI}$ & $B$ coef & $95 \% \mathrm{CI}$ \\
\hline Child's age & & & & & $0.03 * *$ & {$[0.01 ; 0.06]$} \\
\hline QIC & & & & & 49.015 & \\
\hline Single paternal orphan & 1.37 & {$[0.65 ; 2.86]$} & 0.31 & {$[-0.01 ; 0.62]$} & 0.003 & {$[-0.07 ; 0.07]$} \\
\hline Single maternal orphan & 0.80 & {$[0.32 ; 1.96]$} & 0.04 & {$[-0.38 ; 0.45]$} & 0.03 & {$[-0.07 ; 0.12]$} \\
\hline QIC & 482.716 & & $4,816.547$ & & 51.34 & \\
\hline Child's educational aspirations & 1.05 & {$[0.84 ; 1.32]$} & 0.04 & {$[-0.13 ; 0.22]$} & 0.01 & {$[-0.01 ; 0.03]$} \\
\hline QIC & 464.99 & & $4,724.33$ & & 49.397 & \\
\hline Educational plans: planning to start secondary school & 1.59 & {$[0.61 ; 4.16]$} & 0.00 & {$[-0.74 ; 0.75]$} & & \\
\hline QIC & 464.47 & & $4,773.26$ & & & \\
\hline Family cohesion reported by child & 1.00 & {$[0.60 ; 1.66]$} & 0.30 & {$[-0.03 ; 0.63]$} & & \\
\hline QIC & 480.16 & & $4,990.00$ & & & \\
\hline Guardian's reported willingness to build assets & 0.95 & {$[0.84 ; 1.08]$} & & & $-0.03 * * *$ & {$[-0.04 ;-0.01]$} \\
\hline QIC & 479.21 & & & & 48.73 & \\
\hline Number of earners: single-earner family & $0.59 *$ & {$[0.36 ; 0.98]$} & & & & \\
\hline QIC & 478.74 & & & & & \\
\hline Number of children in the household & 1.05 & {$[0.92 ; 1.21]$} & -0.003 & {$[-0.08 ; 0.08]$} & 0.01 & {$[-0.005 ; 0.03]$} \\
\hline QIC & 478.94 & & $4,927.621$ & & 49.19 & \\
\hline Guardian's age & $1.03 *$ & {$[1.01 ; 1.05]$} & 0.01 & {$[-0.01 ; 0.02]$} & 0.001 & {$[-0.001 ; 0.003]$} \\
\hline QIC & 467.65 & & $4,771.67$ & & 49.359 & \\
\hline Guardian's gender: female guardian & 1.72 & {$[0.83 ; 3.55]$} & 0.29 & {$[-0.01 ; 0.60]$} & & \\
\hline QIC & 478.53 & & $4,840.77$ & & & \\
\hline Type of guardian: grandparent & 1.10 & {$[0.48 ; 2.51]$} & -0.21 & {$[-0.57 ; 0.15]$} & $-0.07 *$ & {$[-0.14 ;-0.004]$} \\
\hline Type of guardian: other relatives & $0.45^{*}$ & {$[0.24 ; 0.85]$} & -0.23 & {$[-0.52 ; 0.05]$} & -0.04 & {$[-0.10 ; 0.03]$} \\
\hline QIC & 467.78 & & $4,814.84$ & & 51.22 & \\
\hline Centenary Bank & 0.67 & {$[0.11 ; 4.27]$} & 0.05 & {$[-0.64 ; 0.74]$} & 0.02 & {$[-0.14 ; 0.19]$} \\
\hline DFCU & 1.78 & {$[0.13 ; 23.80]$} & -0.65 & {$[-1.55 ; 0.26]$} & -0.06 & {$[-0.26 ; 0.15]$} \\
\hline QIC & 383.07 & & $4,774.28$ & & 51.37 & \\
\hline QIC for reduced model & 478.16 & & $4,874.85$ & & 47.45 & \\
\hline
\end{tabular}

Boldface type indicates statistically significant results

Italic face type indicates statistically significant effects

${ }^{a}$ Reduced model for having an active CSA includes child's age, Beck Hopelessness Scale, child's knowledge about guardian saving for her/him, and guardian's self-reported saving

${ }^{\mathrm{b}}$ Reduced model for average monthly amount saved includes child's age, Beck Hopelessness Scale, child's knowledge about guardian saving for her/ him, guardian's reported willingness to build assets, guardian's self-reported saving, and number of earners in the family

${ }^{\mathrm{c}}$ Reduced model for frequency of depositing includes: Beck Hopelessness Scale, child's educational plans, family cohesion reported by child, child's knowledge about guardian saving for her/him, guardian's self-reported saving, number of earners in the family, and guardian's gender

$* * * p<0.001, * * p<0.01,{ }^{*} p<0.05$ 


\section{References}

Anong, S. T., \& Fisher, P. J. (2013). Future orientation and saving for medium-term expenses. Family and Consumer Sciences Research Journal, 41(4), 393-412.

Banerjee, A. V., \& Duflo, E. (2007). The economic lives of the poor. The journal of Economic Perspectives, 21(1), 141-167.

Clarke, M. C., et al. (2005). The acquisition of family financial roles and responsibilities. Family and Consumer Sciences Research Journal, 33(4), 321-340.

Cui, J. (2007). QIC program and model selection in GEE analyses. Stata journal, 7(2), 209-220.

Curley, J., Ssewamala, F. M., \& Han, C. K. (2010). Assets and educational outcomes: child development accounts (CDAs) for orphaned children in Uganda. Children and Youth Services Review, 32(11), $1585-1590$

Curto, J. D., \& Pinto, J. C. (2011). The corrected VIF (CVIF). Journal of Applied Statistics, 38(7), 1499-1507.

DeVaney, S. A., Anong, S. T., \& Whirl, S. E. (2007). Household savings motives. Journal of Consumer Affairs, 41(1), 174-186.

Donni, O., \& Chiappori, P.-A. (2011). Nonunitary models of household behavior: a survey of the literature. In J. A. Molina (Ed.), Household economic behaviors (pp. 1--40). New York, NY: Springer.

Friedman, L., \& Wall, M. (2005). Graphical views of suppression and multicollinearity in multiple linear regression. The American Statistician, 59(2), 127-136.

Gudmunson, C. G., \& Danes, S. M. (2011). Family financial socialization: theory and critical review. Journal of family and economic issues, 32(4), 644-667.

Han, C. K., Grinstein-Weiss, M., \& Sherraden, M. (2009). Assets beyond savings in individual development accounts. Social Service Review, 83(2), 221-244.

Han, C. K., Ssewamala, F. M., \& Wang, J. S. H. (2013). Family economic empowerment and mental health among AIDS-affected children living in AIDS-impacted communities: evidence from a randomized evaluation in southwestern Uganda. Journal of Epidemiology \& Community Health, 67, 225-230.

Heckman, J. (2013). Sample selection bias as a specification error. Applied Econometrics, 31(3), 129-137.

Hox, J. (2010). Multilevel analysis: techniques and applications. Hove, UK: Routledge.

Ismayilova, L., Ssewamala, F. M., \& Karimli, L. (2012). Family support as a mediator of change in sexual risk-taking attitudes among orphaned adolescents in rural Uganda. Journal of Adolescent Health, $50(3), 228-235$.

Johnson, L., et al. (2012). Product Pilot Report: Youth savings performance in Ghana, Kenya and Nepal, in YouthSave Research Brief No.12-38, Washington University, Center for Social Development: St. Louis, MO.
Jorgensen, B. L., \& Savla, J. (2010). Financial literacy of young adults: the importance of parental socialization. Family Relations, 59(4), 465-478

Karimli, L., Ssewamala, F. M., \& Ismayilova, L. (2012). Extended families and perceived caregiver support to AIDS orphans in Rakai district of Uganda. Children and Youth Services Review, 34(7), $1351-1358$.

Kim, J., LaTaillade, J., \& Kim, H. (2011). Family processes and adolescents' financial behaviors. Journal of family and economic issues, 32(4), 668-679.

Lin, F.-J. (2008). Solving multicollinearity in the process of fitting regression model using the nested estimate procedure. Quality \& Quantity, 42(3), 417-426.

Mills, G., et al. (2008). Effects of individual development accounts on asset purchases and saving behavior: evidence from a controlled experiment. Journal of Public Economics, 92(5-6), 1509-1530.

Modigliani, F. (2005). The collected papers of Franco Modigliani, volume 6. MIT Press Books. 6.

Oleke, C., Blystad, A., \& Rekdal, O. (2005). "When the obvious brother is not there": political and cultural contexts of the orphan challenge in northern Uganda. Social Science \& Medicine, 61(12), 26282638.

Puri, M., \& Robinson, D. T. (2007). Optimism and economic choice. Journal of Financial Economics, 86(1), 71-99.

Rubin, A., \& Babbie, E. R. (2008). Research methods for social work. Belmont, CA: Cengage Learning.

Schreiner, M., \& Sherraden, M. (2007). Can the poor save? Saving and asset building in individual development accounts. New Brunswick, NJ: Transaction Publishers.

Sherraden, M. (1991). Assets and the poor: a new American welfare policy: ME Sharpe Inc.

Ssewamala, F. M., \& Ismayilova, L. (2009). Integrating children's savings accounts in the care and support of orphaned adolescents in rural Uganda. The Social service review, 83(3), 453-472.

Ssewamala, F. M., et al. (2010a). The potential of asset based development strategies for poverty alleviation in sub Saharan Africa. International Journal of Social Welfare, 19(4), 433-443.

Ssewamala, F. M., et al. (2010b). Gender and the effects of an economic empowerment program on attitudes toward sexual risk-taking among AIDS-orphaned adolescent youth in Uganda. Journal of Adolescent Health, 46(4), 372-378.

Ssewamala, F. M., et al. (2012). The impact of a comprehensive microfinance intervention on depression levels of AIDS-orphaned children in Uganda. Journal of Adolescent Health, 50(4), 346-352.

Webley, P., \& Nyhus, E. K. (2006). Parents' influence on children's future orientation and saving. Journal of Economic Psychology, 27(1), $140-164$.

Webley, P., \& Nyhus, E. K. (2013). Economic socialization, saving and assets in European young adults. Economics of Education Review, 33, 19-30. 